\title{
KEANEKARAGAMAN JENIS GASTROPODA DI HUTAN MANGROVE SUNGAI KAKAP KABUPATEN KUBU RAYA
}

\author{
(Species Diversity of Gastropod in Mangrove Forest of Sungai Kakap District Kubu Raya \\ Regency)
}

\author{
Emanuel Luis Rosario, M. Sofwan Anwari, Slamet Rifanjani, Herlina Darwati \\ Fakultas Kehutanan Universitas Tanjungpura, Jalan Imam Bonjol Pontianak 78124 \\ Email: emanuelluis74@gmail.com
}

\begin{abstract}
Gastropod is one of the mollusk phylum that can adapt and decompose in mangrove forests. The mangrove forest in Sungai Kakap is an area that is slowly being opened due to the local community people's activities. They opened land to build buildings, farms, and villages. This research is aimed at studying the diversity of Gastropod and the influence of the mangrove tree density on the gastropod diversity in the mangrove forest of Sungai Kakap, Sungai Kakap Village of Kubu Raya Regency. The data were taken in May 2018. The analysis was conducted using the observation method by making six observation lines. The lines were differentiated based on the density of the vegetations: dense, medium, and sparse. The number of Gastropods found in the Kakap River mangrove forest is 4 types of gastropods with a total of 252 individuals. Respectively from dense, medium, and sparse vegetation, the gastropod dominance index is 0.68,0.37, and 0.51 ; the diversity index is $0.25,0.49$, and 0.33 ; the species average index is $0.27,0.97$, and 0.4; and the gastropod species richness index is 4.03, 1.18, and 0.7. Lastly, the species similarity index is respectively $86 \%, 66 \%$, and $86 \%$.
\end{abstract}

Keywords: Gastropod, Mangrove Forests, Vegetation density.

\section{PEDAHULUAN}

Hutan mangrove adalah tumbuhan daratan berupa semak-semak belukar dan pohon-pohon yang bertahan hidup dan beradaptasi dengan cara yang luar biasa pada kondisi asin (Parida and Jha, 2010). Hutan mangrove merupakan vegetasi yang dapat bertahan hidup di kawasan perairan payau. Hutan mangrove memiliki kekayaan yang melimpah mulai dari jenis flora dan fauna. Fauna yang dimanfaatkan manusia untuk bahan pakan pada kawasan hutan mangrove antara lain seperti siput (gastropoda) dan kerang (bivalvia).
Moluska merupakan hewan lunak yang mempunyai cangkang dan banyak ditemukan pada ekosistem mangrove yang hidup di permukaan substrat maupun di dalam substrat dan menempel pada pohon mangrove (Hartoni dan Agussalim, 2013). Gastropoda merupakan hewan yang masuk ke dalam filum moluska dan berhabitat di hutan mangrove. Umumnya Gastropoda yang sering kita jumpai memiliki cangkang berbentuk tabung spiral, bentuk tubuh asimetris, pernafasan menggunakan ingsang dan anatomi internal disebut torson (FAO, 1983). Fungsi ekologis gastropoda yakni menjadi bioindikator 
kestabilan ekosistem mangrove sebagai dekomposer serasah daun, bangkai, partikel sedimen, diatom bentik dan bakteri (Penha-Lopes, et al, 2009)

Kelas gastropoda beradaptasi baik di mangrove, jika memiliki keanekaragaan dan jumlah individu rendah, maka dapat dipastikan ekosistem hutan mangrove terganggu. Berkurangnya gastropoda akan mengurangi proses dekomposisi di hutan mangrove, yang berdampak pada berkurangnya sedimentasi yang didapat dari sisa-sisa kosumsi Gastropoda. Gastropoda dapat menjadi bioindikator dari kerusakan hutan mangrove, apabila kondisi mangrove bagus maka keanekaragaman dan jumlah invidu gastropoda tinggi, begitu juga sebaliknya.

Hutan mangrove Sungai Kakap adalah daerah yang kaya akan sumber daya alam baik flora mau pun fauna, seperti ikan, kepah, siput dan nipah. Masyarakat sekitar menggantungkan hidupnya pada kawasan hutan mangrove, akan tetapi kondisi hutan mangrove Sungai Kakap saat ini memprihatinkan. Penurunan kualitas disebabkan adanya aktivitas warga masyarakat sekitar kawasan hutan mangrove. Masyarakat memanfaatkan hutan mangrove untuk kebutuhan hidup dan pengalokasian hutan menjadi lahan pemukiman. Maraknya ekploitasi hutan mangrove yang dilakukan oleh manusia berdampak buruk terhadap ekosistem mangrove, mulai dari hilangnya tegakan dan berkurangnya hewan yang bernaung di dalam tegakan, seperti ikan dan kelas Gastropoda. Hutan mangrove yang rusak tidak lagi dapat menahan abrasi yang terjadi, apabila hal ini terus terjadi maka kawasan daratan Sungai Kakap akan terus terkikis oleh air dan akan terjadi banjir pada saat air pasang. Tujuan penelitian ini adalah mengkaji keanekaragaman jenis gastropoda pada kawasan hutan mangrove Sungai Kakap Kabupaten Kubu Raya dan mengkaji pengaruh kerapatan pohon terhadap keanekaragaman jenis gastropoda di kawasan hutan mangrove Sungai Kakap Kabupaten Kubu Raya.

\section{METODE PENELITIAN}

Pengambilan data dilakukan di hutan mangrove Sungai Kakap, Desa Sungai Kakap Kecamatan Sungai Kakap Kabupaten Kubu Raya pada bulan mei 2018. Kajian keanekaragaman jenis gastropoda dilakukan menggnakan metode observasi dengan membuat 6 jalur dengan jarak antar jalur 50meter. Setiap jalur dibuat masing-masing 10 plot pengamatan dengan jarak antar plot 10meter dan ukuran $1 \mathrm{x} 1 \mathrm{~m}^{2}$. Enam jalur pengamatan dibuat pada keadaan hutan mangrove yang berbeda yaitu 2 jalur pada vegetasi rapat, 2 jalur pada vegetasi sedang dan 2 jalur pada vegetasi jarang. Indentifikasi gastropoda menggunakan panduan The Living Marine Pacific (FAO 1998). 


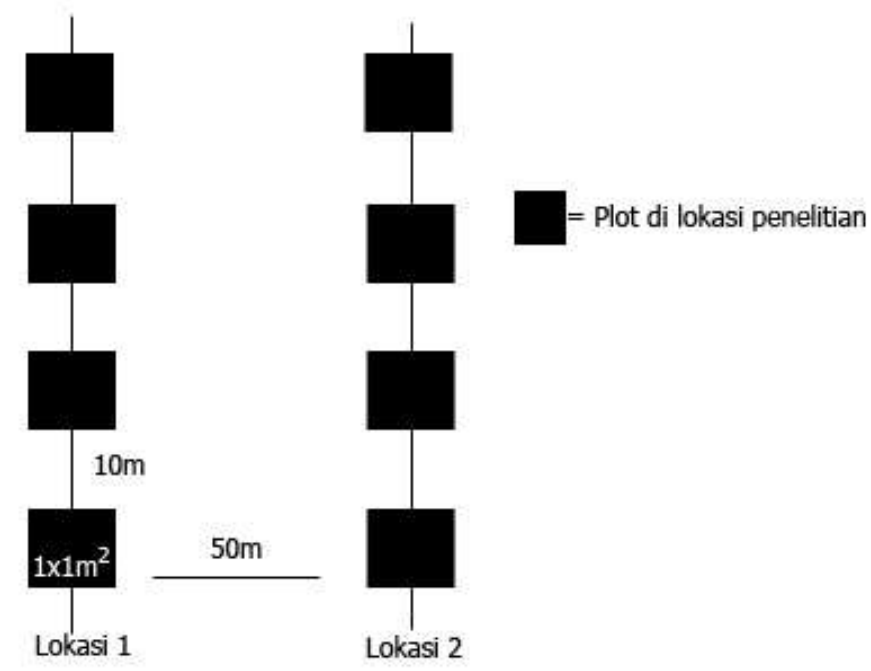

Gambar 1. Skema Transek di lokasi Penelitian (Transect Scheme at the Research Site)

Data utama yang dikumpulkan peneliti adalah: Jumlah gastropoda, jenis gastropoda, kerapatan vegetasi, sedimen/serasah, $\mathrm{pH}$ tanah dan Intensitas cahaya. Analisis menggunakan indeks dominasi, keanekaragaman, kemerataan, kekayaan dan kesamaan jenis.

a. Indeks dominansi (Simpson Index) Indeks dominansi digunakan untuk menentukan dominasi suatu jenis satwa yang terpusat dalam komunitas digunakan rumus sebagai berikut (Odum, 1996)

$$
\mathrm{C}=\sum\left(\frac{n i}{N}\right)^{2}
$$

Dimana :

C $=$ Indeks Dominansi

ni = Jumlah individu

$\mathrm{N}$ = Jumlah individu seluruh jenis

Indikator menurut (Odum, 1971)

$C<0,5=$ berarti tidak terdapat jenis yang mendominasi jenis lainnya
C $>0,8=$ berarti terdapat jenis yang mendominasi jenis lainnya

b. Indeks Keragaman Jenis

Suatu jenis indeks secara keseluruhan dapat ditentukan denganrumus Shanon- Wiener (Odum, 1996) sebagai berikut :

$\mathrm{H}^{\prime}=-\sum\left\{\left(\frac{n i}{N}\right) \log \left(\frac{n i}{N}\right)\right\}$

Dimana :

$\mathrm{H}^{\prime}=$ Indeks keanekaragaman Shanon- Wiener

ni = Jumlah Individu suatu jenis

$\mathrm{N} \quad=$ Jumblah individu seluruh jenis

Besarnya indeks keanekaragaman jenis menurut Shannon-Wienner didefinisikan sebagai berikut :

Nilai $(\mathrm{H}) \quad=$

$0<\mathrm{H}^{\prime}<1$ Keanekaragaman rendah

$1<\mathrm{H}^{\prime}<3$ Keanegaragaman Sedang

$\mathrm{H}^{\prime}>3$ Keanekaragamaan tinggi

c. Indeks Kemerataan 
Indeks kemerataan digunakan untuk menentukan tingkat kelimpahan satu jenis dipengaruhi oleh keberagaman atau nilai kemerataan dalam pembagian jenis yang merata diantara jenis yang ada dalam satu komunitas. Indeks kemerataan dapat ditentukan dengan mengunakan rumus ShanonWiener (Odum, 1996) adapun rumus indeks kemerataan adalah sebagai berikut :

Dimana :

$$
\mathrm{e}=\mathrm{H}^{\prime} / \log \mathrm{S}
$$

$\begin{array}{ll}\mathrm{e} & =\text { Indeks Kemerataan } \\ \mathrm{H}^{\prime} & =\text { Indeks keanekaragaman }\end{array}$

Shanon- Wiener

$\mathrm{S} \quad=$ Jumlah jenis yang teramati

Nilai indeks berkisar 0-1

$\mathrm{E}=0$, berarti kemerataan jenis rendah

$\mathrm{E}=1$, berarti kemerataan antar jenis relatif merata/sama

d. Indeks Kekayaan Jenis

Merupakan nilai atau rasio perbandingan jenis antara jumlah jenis secara keseluruhan terhadap jumlah individu jenis yang dijumpai (Odum, 1996) dengan rumus sebagai berikut :

$$
\mathrm{D}=\frac{S-1}{\log N}
$$

Dimana :

$\mathrm{d} \quad=$ Indeks kekayaan jenis

$\mathrm{S}=$ Jumlah jenis yang teramati

$\mathrm{N}=$ Jumlah individu seluruh jenis
Indeks kekayaan jenis untuk nilai lebih dari 3,5 digolongkan sedang dengan nilai indeks 1,5 - 3,5 dan tergolong rendah dengan nilai indeks kurang dari 1,5.

e. Indeks kesamaan jenis

Untuk melihat kesamaan jenis dalam suatu komunitas, digunakan rumus indeks kesaman jenis menurut Sorensen ( Soerianegara dan Indrawan, 1982)

$$
\mathrm{IS}=\frac{2 W}{A+B} x 100 \%
$$

$\mathrm{S}=$ Indeks kesamaan jenis

A = Jumlah Jenis di Lokasi a

$\mathrm{B}=$ Jumlah Jenis di Lokasi $\mathrm{b}$

$\mathrm{W}=$ Jumlah spesies yang sama pada dua lokasi.

Nilai indikator jika IS= 1 berarti pada dua habitat yang dibandingkan terdapat kesamaan identik dalam hal jenis gastropoda yang ditemukan

HASIL DAN PEMBAHASAN

\section{Gastropoda di Hutan Mangrove}

Sungai Kakap

Kondisi daerah penelitian berdasarkan kerapatan vegetasi pada saat penelitian dikategrikan menjadi 3 yaitu :

Vegetasi rapat dijumpai 3 famili yaitu Naticidae, Potamididae dan Neritidae dengan 173 individu. Lokasi penelitian ini banyak dijumpai enceng gondok dan sampah plastik, pada daerah ini terjadi pengalokasian lahan dari hutan mangrove menjadi perkebunan kelapa. 


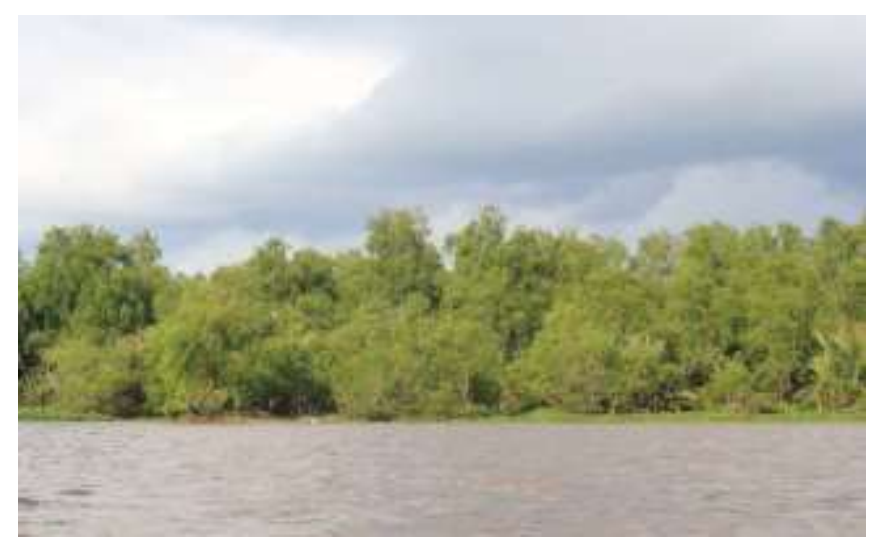

Gambar 2. Kondisi Vegetasi Rapat (dense vegetation conditions)

Vegetasi sedang dijumpai 4 famili yaitu Naticidae, Potamididae, Neritidae dan Onchidiidae sp dengan 49 individu. Lokasi penelitian ini banyak dijumpai sampah plastik dan terjadi pengalokasian lahan dari hutan mangrove menjadi perkebunan kelapa.

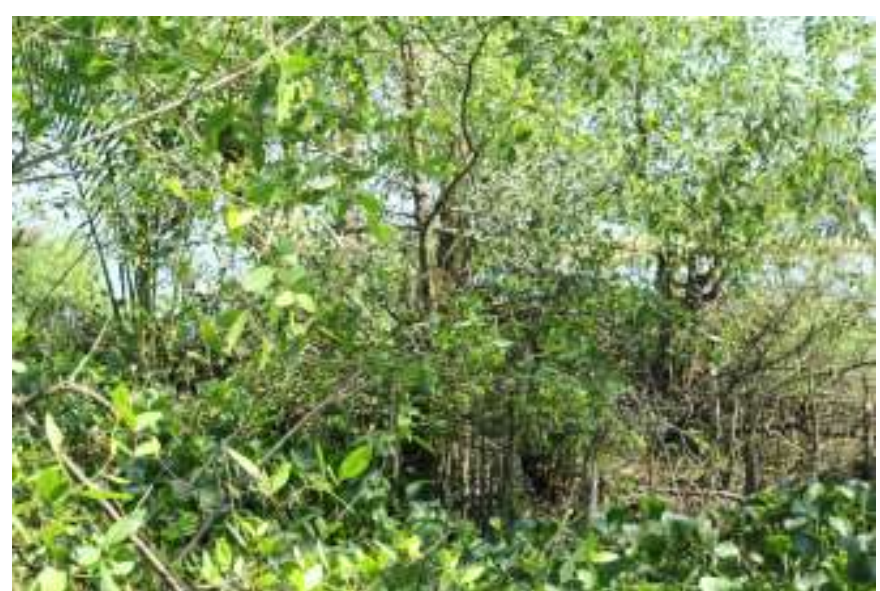

Gambar 3. Kondisi Vegetasi Sedang (Medium vegetatation conditions)

Vegetasi jarang dijumpai 3 famili yaitu Potamididae, Neritidae dan Onchidiidae $s p$ dengan 30 individu. Lokasi penelitian ini banyak dijumpai Nipah dan sampah plastik, pada daerah ini juga terjadi pengalokasian lahan dari hutan mangrove menjadi perkebunan kelapa dan lahan untuk bangunan pemukiman. 


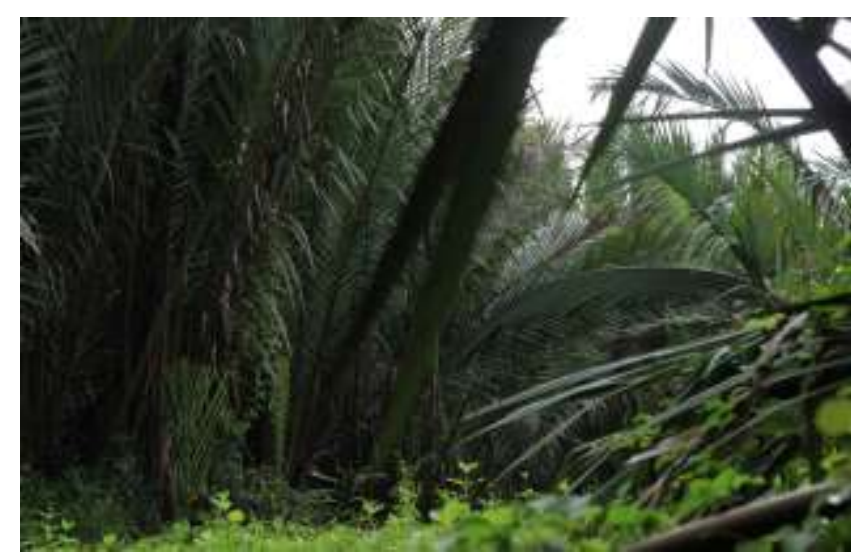

Gambar 4. Kondisi Vegetasi Jarang (open vegetation conditions)

Hasil penelitian di hutan mangrove Sungai Kakap memperoleh total 252 individu gastropoda yang terdiri atas 4 spesies yaitu : Natica gualteriana,
Cerithidea cingulata, Nerita articulata dan Onchidium $s p$ pada 6 jalur pengamatan.

Tabel 1. Gastropoda yang Ditemukan di Hutan Mangrove Sungai Kakap (Gastropods found in Sungai Kakap mangrove forest)

\begin{tabular}{|c|c|c|c|c|c|}
\hline Jalur & $\begin{array}{l}\text { Vegetasi } \\
\text { Mangrove }\end{array}$ & Nama Lokal & Jenis & Family & Jumlah \\
\hline \multirow{3}{*}{$\begin{array}{c}2 \\
\text { dan } \\
3\end{array}$} & \multirow{3}{*}{ Rapat } & Siput gepeng kecil & Natica gualteriana & Naticidae & 7 \\
\hline & & Siput lancip & Cerithidea cingulata & Potamididae & 140 \\
\hline & & Siput gepeng & Nerita articulata & Neritidae & 26 \\
\hline \multirow{4}{*}{$\begin{array}{c}1 \\
\text { dan } \\
5\end{array}$} & \multirow{4}{*}{ Sedang } & Siput gepeng kecil & Natica gualteriana & Naticidae & 26 \\
\hline & & Siput lancip & Cerithidea cingulata & Potamididae & 11 \\
\hline & & Siput gepeng & Nerita articulata & Neritidae & 10 \\
\hline & & Siput tak bercangkang & Onchidium sp & Onchidiidae sp & 2 \\
\hline \multirow{3}{*}{$\begin{array}{c}4 \\
\text { dan } \\
6\end{array}$} & \multirow{3}{*}{ Jarang } & Siput lancip & Cerithidea cingulata & Potamididae & 10 \\
\hline & & Siput tak bercangkang & Onchidium $s p$ & Onchidiidae sp & 1 \\
\hline & & Siput gepeng & Nerita articulata & Neritidae & 19 \\
\hline \multicolumn{5}{|c|}{ Jumlah } & 252 \\
\hline
\end{tabular}

Lokasi penelitian hutan mangrove Sungai Kakap jalur yang memiliki vegetasi rapat adalah jalur 2 dan 3 sedangkan jalur yang memiliki kerapatan vegetasi sedang adalah jalur 1 dan 5 serta jalur yang memiliki kerapatan vegetasi yang jarang adalah jalur 4 dan 6 . Pengambilan data dengan ukuran plot 1x1m, jarak antar jalur 50m dan jarak antar plot $10 \mathrm{~m}$. Hasil pengamatan jenisjenis gastropoda yang ditemukan di hutan mangrove Sungai Kakap adalah 
Natica gualteriana, Cerithidea cingulata, Nerita articulata dan Onchidium sp. Jenis yang banyak di temukan di hutan mangrove Sungai Kakap adalah Cerithidea cingulata dengan jumlah individu sebanyak 161

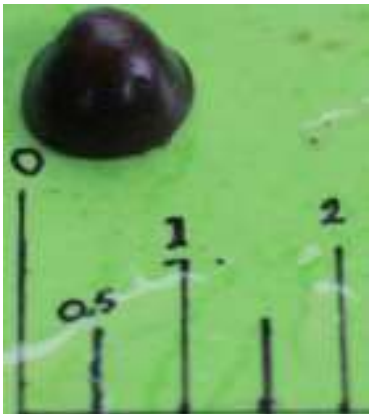

( a )

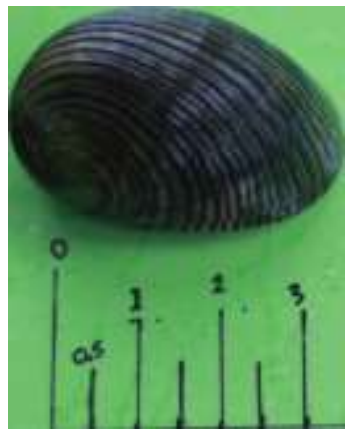

(c) dan spesies yang paling sedikit ditemukan adalah Onchidium sp dengan jumlah sebayak 3 individu. Jenis-jenis gastropoda tersebut disajikan pada gambar 3.

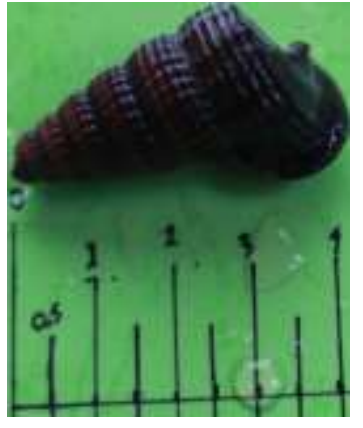

( b )

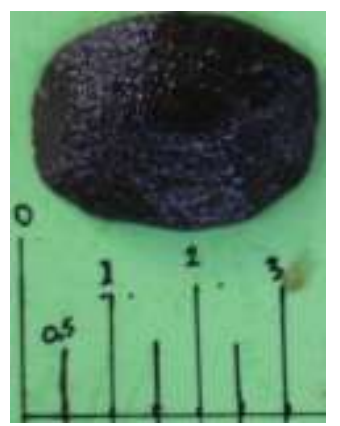

( d )

Gambar 5 . Jenis Gastropoda yang ditemukan di hutan mangrove Sungai Kakap ( Gastropods foud at Sumgai Kakap Mangrove Forest) ( a ) Natica gualteriana. ( $b$ ) Cerithidea cingulata. ( $c$ ) Nerita articulata. Dan ( $d$ ) Onchidium sp.

Nilai Indeks dominansi, Keanekaragaman jenis, Kemerataan dan Kekayan Jenis pada hutan Mangrove Sungai Kakap dengan Vegetasi Rapat, Sedang dan Jarang.

\begin{tabular}{ccccc}
\hline Vegetasi & Dominansi & $\begin{array}{c}\text { Keanekaragaman } \\
\text { Jenis }\end{array}$ & Kemerataan & $\begin{array}{c}\text { Kekayaan } \\
\text { Jenis }\end{array}$ \\
\hline Rapat & 0,68 & 0,25 & 0,27 & 4,03 \\
Sedang & 0.37 & 0,49 & 0,97 & 1,18 \\
Jarang & 0,51 & 0,33 & 0,4 & 0,7 \\
\hline
\end{tabular}

Hutan mangrove Sungai Kakap memiliki nilai dominansi tertinggi pada vegetasi rapat dengan nilai 0,68 , pada vegetasi sedang memiliki nilai 0,37 dan pada vegetasi jarang memiliki nilai 0,51 . Pada ke tiga vegetasi, tidak terdapat jenis 
gastropoda yang mendominasi karena tidak mencapai nilai $\mathrm{C}>0,8$ (Odum,1996). Kurang dominansi pada hutan mangrove Sungai Kakap diakibatkan banyaknya sampah plastik pada kawasan ini. Plastik merupakan tipe sampah laut dominan (CBD-STAP 2012). Sampah plastik berdampak pada hutan mangrove, tumpukan plastik memenuhi tempat untuk berkembang biaknya bibir mangrove muda dan melambatkan regenerasi hutan mangrove muda akibat hilangnya media tumbuh. Kerusakan ekosistem mangrove berdampak pada satwa yang bernaung didalamnya.

Indeks Keanekaragaman di hutan mangrove Sungai Kakap memiliki nilai 0,25 pada vegetasi rapat, 0,49 pada vegetasi sedang dan 0,33 pada vegetasi jarang. Nilai indeks kenaekaragaman gastropoda sangat rendah karena pada ke 3 vegetasi berkisar antara 0,25-0,49. Menurut (Odum, $0<H^{\prime}<$ keanekaragaman rendah. Pada 3 vegetasi keanekaragamannya rendah dikarenakan banyaknya sampah yang berada pada semua kawasan. Hutan mangrove Sungai Kakap juga memiliki vegetasi yang terbuka akibat perubahan fungsi lahan antara lain kebun kelapa, pemanfaatan pohon untuk bahan bangunan dan pemukiman. Mangrove bersifat kompleks karena ekosistemnya dipenuhi oleh vegetasi, mangrove juga merupakan habitat bagi satwa dan biota perairan. Mangrove bersifat dinamis karena hutan mangrove dapat tumbuh dan berkembang terus menerus serta mengalami suksesi sesuai dengan perubahan tempat tumbuh alaminya, akan tetapi bersifat labil karena mudah sekali rusak dan sulit pulih seperti sediakala (Kusmana, 2002). Keanekaragaman gastropoda di hutan mangrove Pantai Si Runtoh Taman Nasional Baluran memiliki nilai yang berbeda-beda pada setiap jalur pengamatan, faktor yang mempenharuhinya adalah lokasi topografi dan habitat dimasing-masing jalur. Jalur 4 memiliki nilai tertinggi yaitu dengan nilai 0,728 pada penelitian tersebut, hal itu diakibatkan pada jalur 4 memiliki kerapatan mangrove yang tinggi sehingga ketika air pasang akan terpecah oleh akar mangrove yang menyebabkan berkurangnya tekanan arus sehingga gastropoda tidak terbawa arus saat pasang (Fitri Retnananing Siswi, 2017).

Indeks Kemerataan di hutan mangrove Sungai Kakap memiliki nilai 0,27 pada vegetasi rapat, 0,97 pada vegetasi seadng dan 0,4 pada vegetasi jarang. Spesies dikatakan merata apabila indeks kemerataan $=1($ Soegianto, 1994), nilai indeks kemerataan dihutan mangrove Sungai Kakap berkisar antara 0,27-0,97 yang berarti kemerataan jenis relatif tidak merata. Kemerataan jenis dihutan mangrove Sungai Kakap memiliki nilai rendah karena kerusakan hutan akibat alih fungsi lahan menjadi perkebunan kelapa dan lahan bangunan. Hutan mangrove adalah suatu komponen yang kompleks, kerusakan hutan mangrove akan mempengaruhi satwa yang bernaung didalamnya. 
Indeks kekayaan jenis di hutan mangrove Sungai Kakap memiliki nilai 4,03 pada vegetasi rapat, 1,18 pada vegetasi sedang dan 0,7 pada vegetasi jarang. Hutan mangrove Sungai Kakap memiliki nilai indeks kekayaan jenis berkisar antara 0,7-4,03 yang artinya pada vegetasi rapat memiliki kekayaan jenis yang kaya dan pada vegetasi sedang serta jarang memiliki indeks kekayaan jenis yang kurang. Pengaruh dari keadaan vegetasi dan plot yang dianalisis dihutan mangrove Sungai Kakap menyebabkan kekayaan jenis di vegetasi rapat dikategorikan sedang. Keadaan vegetasi pada kondisi sedang dan jarang, banyak dijumpai sampah dan plot yang dianalisis ada pengalih fungsi lahan dari hutan mangrove menjadi lahan perkebunan.

\section{Indeks Kesamaan Jenis}

Indeks kesamaan jenis pada kerapatan vegetasi rapat dan sedang memiliki dengan nilai $86 \%$, maka pada vegetasi rapat dan sedang terdapat kesamaan jenis gastropoda. Vegetasi rapat dan jarang memiliki indeks kesamaan jenis dengan nilai $66 \%$. Vegetasi rapat dan jarang memiliki nilai IS $66 \%$, maka pada vegetasi rapat dan sedang terdapat kesamaan jenis gastropoda. Vegetasi sedang dan jarang memiliki indeks kesamaan jenis dengan nilai $86 \%$. Vegetasi sedang dan jarang memiliki nilai IS 86\%, maka pada vegetasi rapat dan sedang terdapat kesamaan jenis gastropoda. Indeks Kesamaan Jenis dihutan mangrove Sungai Kakap memiliki kesamaan jenis pada setiap vegetasinya, keadaan lokasi pengamatan yang ada dan kondisi lokasi pengamatan yang memiliki masalah yang sama menyebabkan jenis-jenis tertentu saja yang dapat bertahan hidup di hutan mangrove Sungai Kakap.

\section{KESIMPULAN}

Hutan mangrove Sungai Kakap ditemukan 4 jenis gastropoda yaitu Natica gualteriana, Cerithidea cingulata, Nerita articulata dan Onchidium sp. Indeks dominansi pada vegetasi hutan rapat, sedang dan jarang tidak ada jenis yang mendominasi jenis lainnya. Indeks keanekaragamaan, Indeks kemerataan dan Indeks kekayaan jenis pada ketiga lokasi pengamatan adalah tergolong rendah.

\section{SARAN}

Perlu adanya kesadaran untuk memanfaatkan hutan lebih bijak dan sosialisasi tentang pentingnya hutan serta dampak sampah plastik terhadap gastropoda. Perlu penangan khusus terhadap pencemaran sampah plastik yang terjadi di hutan mangrove Sungai Kakap dari lembaga terkait, baik dari pemerintah dan NGO yang bergerak dalam sektor konservasi. Perlu adanya penelitian lanjutan yang lebih spesifik terkait faktor yang berpengaruh terhadap rendahnya keanekaragamn gastropoda di hutan mangrove Sungai Kakap.

\section{DAFTAR PUSTAKA}

Convenetion on Biological Diversity; Scientific and Technical Advisory Panel (CBD; STAP). 2012. Impacts of Marine Debris on Biodiversity: Current Status and Potential Solutions. CBD Technical Series No. 67. Secretariat of the Convention of 
Biological Diversity. Montreal (CA).

Food Agriculture Organization (FAO). 1983. Ecology of Mangroves. University of Queensland, London.

Fitri, R. S. 2017. Keanekaragaman dan Kepadatan Gastropoda di Hutan Mangrove Pantai Si Runtoh Taman Nasional Baluran. Jurnal ILMU DASAR, Vol.18 No 2,Juli 2017:119-124.

Hantoni \& Agussalim A. 2013. Komposisi dan Kelimpahan Moluska (Gastropoda dan Bivalvia) di Ekosistem Mangrove Muara Sungai Musi Kabupaten Banyuasin Provinsi Sumatra Selatan, Maspari Journal. 5 (1): 615.
Odum, E. P 1996. Dasar-dasar ekologi edisi ketiga. Universitas Gajahmada Yogyakarta.

Parida A K \& Jha, B. 2010. Salt tolerance mechanisms in mangroves: a review. Trees, 24(2): 199-217.

Penha-Lopes, G., S. Bouillon, P. Mangion, A. Macia, J. Paula. 2009. Population structure, density and food sources of Terebralia palustris(Potamididae;Gastropoda ) in a low intertidal Avicennia marina mangrove stand (Inhaca Island,Mozambique). Estuarine, Coastal and Shelf Science 83 (3):318-325.

Soegianto A, 1994. Ekologi Kwantitatif metode Analisis Populasi Komunitas. Surabaya. Usaha Nasional. 